\title{
Not Just Cyberwarfare
}

\author{
Bruce Christianson ${ }^{1}$
}

Received: 26 February 2015 / Accepted: 6 March 2015 /Published online: 28 March 2015

(C) Springer Science+Business Media Dordrecht 2015

\begin{abstract}
Bringsjord and Licato provide a general meta-argument that cyberwarfare is so different from traditional kinetic warfare that no argument from analogy can allow the just war theory of Augustine and Aquinas (hereinafter called JWT) to be pulled over from traditional (modern) warfare to cyberwarfare. I believe that this metaargument is sound and that it applies not just to cyberwarfare: in particular, on my reading of the meta-argument, argument from analogy has never been adequate to allow JWT to be applied to the kind of warfare that we are familiar with now.
\end{abstract}

Combat epistemologists and violin soloists both are underpaid, but take many years and no little innate talent to train. Consequently, the demands on their time are many.

- Charles Stross, Equoid

All language, including formal language, is metaphorical, and any metaphor misleads if it is pushed too far. ${ }^{1}$ A similar point applies to arguments by analogy: when the correspondences upon which the analogy rests cease to be close enough, the analogy becomes false.

The target paper (Bringsjord \& Licato 2015) provides a general meta-argument, to the effect that cyber warfare is so different from traditional kinetic warfare (and from traditional espionage) that no argument from analogy can, even in principle, allow the just war theory of Augustine and Aquinas (hereinafter called JWT) to be pulled over from traditional (modern) warfare so as to apply in any exploitable way to the emerging realm of cyberwarfare.

\footnotetext{
${ }^{1}$ Whatever one may think about the rest of the book, Jaynes (1976) gives an excellent account of the way in which metaphors are parameterized.

Bruce Christianson

b.christianson@herts.ac.uk

1 University of Hertfordshire, Hatfield, Herts, UK
} 
I believe that this meta-argument is sound: indeed, I believe that the meta-argument is a great deal stronger than the target paper admits, and that it applies not just to cyberwarfare.

On my reading of the meta-argument, analogy is incapable of enabling JWT to cross many other fissures of innovation that run across the history of war: in particular, argument from analogy has never been adequate to allow JWT to be applied to the kind of warfare that we are familiar with now.

Of course, this does not mean that the JWT of Augustine and Aquinas cannot be applied to modern warfare or even to cyberwarfare ${ }^{2}$ : it means simply that the programme of doing so by means of exploiting analogies is doomed. However, the metaargument of the target paper does, in my view, sweep away at a stroke much of the vast superstructure erected by later commentators upon the Aquinian foundation for JWT.

I want to argue that there have been many other occasions upon which, according to the target paper meta-argument, the application of JWT by analogy has in fact been invalid. However, the example that I shall consider in a little detail is the widespread deployment of the crossbow at the beginning of the first crusade, viewed in the light of the essential criteria set out in section 5.1 of the target paper.

Crossbows had been in existence since antiquity, ${ }^{3}$ but what was radically new in 1095 was their abrupt ubiquity. Suddenly, an army of peasants was equipped with a cheap, mass-produced weapon capable of pushing a reusable metal bolt through the armour of a knight on horseback (and through the knight inside), from a sufficient distance (over a hundred yards) that the knight had very few effective countermoves available.

In dramatic contrast to the armoured knight on horseback, who required a coterie of armourers, farriers, blacksmiths, and squires to keep him battle-ready, a crossbowman required almost no infrastructure. All of their equipment was easily replaceable, used interchangeable parts, and could be carried by one person across rough terrain. ${ }^{4}$

The crossbow did not require great physical strength, ${ }^{5}$ nor did it require extensive training or practice. A peasant could be re-tasked from agricultural labourer to crossbow user with about a week of training; almost none of it devoted to learning the complex rules of chivalry.

The organisers of the first crusade had no clear understanding of the consequences of unleashing an army of peasants armed in this way. The motivations and agenda of the peasants were not understood or adequately modelled by those responsible for arming them: in particular, it was not clear whether they would be more likely to use the crossbows against the nominal enemy, against the feudal lords on what was ostensibly their own side, ${ }^{6}$ or against non-combatants with covetable possessions.

A horde of peasants armed with crossbows was intrinsically impossible to control, given that they now had the means to overturn the natural order of society, and that none of the traditional elites had any insight into their motivations. They were therefore immoral to deploy.

Although the Pope took the precaution of excommunicating ${ }^{7}$ in advance anyone who used a crossbow against a fellow Christian, it was inevitable that they eventually would be.

\footnotetext{
${ }^{2}$ An observation that the target paper itself carefully makes, in footnote seven.

${ }^{3}$ Just as computer-based cyber-systems have already been involved in warfare for over 60 years.

${ }^{4}$ Although for tactical convenience, crossbowmen usually operated in groups of three.

${ }^{5}$ Indeed, it is clear that women could, and did, use it: a point to which I shall return below.

${ }^{6}$ Who no longer had an effective means of prevailing against them.

${ }^{7}$ Urban II in 1096, at the start of the first crusade.
} 
The wagers of the war did not have an adequate understanding of the effects of their widespread deployment of crossbowman who were effectively autonomous. For all the organisers of the crusade could know, the result might be harm that was unimaginably severe and entirely chaotic.

Nor was it any longer clear who was a combatant and who was not. The crossbow, by its readily accessible nature, blurred the distinction between a combatant and a non-combatantall one had to do was pick one up. It is mainly from Muslim accounts that we learn of occasions when crossbows were wielded to great effect by crusader women: indeed these accounts praise the prowess as well as the courage of the women concerned. ${ }^{8}$ The corresponding Christian accounts generally confine the activities of the women to acting as water carriers. ${ }^{9}$

Was it really clear at the start of the first crusade - indeed, did the organisers have any way by which they could have known - that the crossbow users would not propagate across the world, indiscriminately inflicting horrific injuries on combatants and non-combatants alike?

Surely, by the meta-argument of the target paper, analogy with pre-crusade experience cannot justify the application of JWT to warfare involving widespread use of the crossbow.

At this point, it could be objected that I have perpetrated a temporal paradox. After all, it was the crusades that bought back to the West the lost texts of Aristotle, and many other manuscripts, together with the Arab commentaries on them. As well as revitalising western intellectual thought, it was these commentaries that made necessary, as well as possible, Aquinas' synthesis of Aristotelian philosophy with the neoPlatonist theology of the Christian church. ${ }^{10}$

Surely, it could be argued, since Aquinas' version of JWT postdates the widespread deployment of the crossbow, it is ludicrous to argue that JWT cannot be pulled by analogy from the period before widespread use of the crossbow to the period immediately after. After all, Aquinas must have developed his account of JWT with the crossbow in mind.

I could, instead of the crossbow, instance post-Aquinian innovations such as the machine gun, ${ }^{11}$ the tank, or drones. But actually, I don't think the objection is valid. Suppose counterfactually that Aquinas confesses to copying his JWT wholesale from an earlier Arab work, written before use of the crossbow became widespread. Does this mean the meta-argument suddenly applies and that the JWT of the crossbow is not analogous to that of previous warfare after all?

What if the Arab source in turn admits to obtaining JWT from a time traveller ${ }^{12}$ moving backwards from the period following the widespread deployment of cyberwarfare? Does that mean that the meta-argument now fails with respect to using analogy to pull JWT across the introduction of cyberwarfare? Is the application of JWT simply a matter of deploying methods of mass destruction immorally for a while, until we know enough about them to make the required analogies work?

Clearly not. The meta-argument from dis-analogy, in the terms in which it is formulated in the target paper, doesn't give such epistemic hostages. It is a formal ${ }^{13}$ argument: it either works or it doesn't.

\footnotetext{
${ }^{8}$ Their gender typically being revealed only when their corpse was stripped by the enemy.

${ }^{9}$ See Caspi-Reisfeld (2001) for more on this.

${ }^{10}$ See Moody (1958) for more on this.

11 The AK47 was designed to be repaired in field situations using replacement components fabricated with a pocket knife from empty tin cans.

${ }^{12}$ Possibly a photon-based cyber-intelligence.

13 That is, depending only on form.
} 
The target paper is at pains to point out (section 5.2) that the meta-argument regarding cyberwarfare does not require machines to be capable of acquiring subjective awareness, self-consciousness, or human-level creativity. I regard the question whether machines can possess these attributes as falling into the same category as asking whether women have souls. ${ }^{14}$ It is an interesting question, but not for any of the obvious reasons, and good theology does not always make for good metaphysics. ${ }^{15}$ However, in the present context, the more interesting questions are, how effectively can a woman use a crossbow, or can WatsonQA command a tank? And what will they use it to do?

There are two points at which I believe the target paper overstates the case, although neither of these is central to the meta-argument. The first is where it gives the impression that all that matters about the physical objects involved in cyberwarfare, and the complex computations that cloak them, is what they can actually do.

However, war is diplomacy by other means, and weapons are deployed not only in order to enable them to be actually used but also in order to give rise to beliefs by other participants about the possibilities for their use. This, in turn, leads adversaries to beliefs that particular moves on their part will place them in an untenable position. Now, these sets of engendered beliefs also matter but need not be mutually interconsistent. The authors of the target paper have made it clear elsewhere that they are alive to the nuances of modelling such intensional attitudes, ${ }^{16}$ and their present argument would benefit if they were to take a little more of their own medicine in this regard.

The second point where I find the target paper implausible is its view that in the future, all kinetic weapons will be buried under complex cyber layers of software: indeed, I believe that the argument of the target paper shows exactly why this will never be allowed to happen. Kinetic weapons of a "conventional" kind will continue to be available because when both sides have knocked out each other's software, the matter will necessarily be decided by manual combat as it always has been.

In summary then, the authors have produced a very interesting and lively metaargument, which I believe demonstrates that the modern analysis of just war theory has never been valid, relying as it does on invalid use of analogies. The JWT arguments of Augustine and Aquinas are a great deal more adaptable than their advocates give them credit for: the meta-argument leaves Augustine and Aquinas standing, but it demolishes most of their commentators, particularly the more recent ones.

\footnotetext{
${ }^{14}$ For the $\mathrm{C} 17$ version of this debate, see Valens Acidalius and Arcangelica Tarabotti (Acidalius 1647; Tarabotti 1651).

${ }^{15}$ Creation from nothing being a case in point. One casualty of the move to teaching philosophy from the analytic rather than the historical perspective has been the almost complete disappearance of aesthetics from the undergraduate philosophy curriculum, thus allowing one of the most convenient bridges between ethics and metaphysics to fall into disrepair. A world in which women, or cyber-systems, are treated on essentially unequal terms to the rest of us is an uglier world.

${ }^{16}$ See footnotes 8 and 14 of the target paper, and Arkoudas \& Bringsjord (2009) which is referenced from footnote 8 .
} 
Where to next? I would like to see the authors move their argument further, from the process of analogy to that of abstraction and from analysing truth of propositions to constraining meanings for predicates.

\section{References}

Acidalius, V. (writing as Horatio Plato). (1647). Che le donne non habbino anima e che non siano della specie degli huomini, e vienne comprobato da molti luoghi della Scrittura santa [Women do not have a soul and do not belong to the human race, as is shown by many passages of holy Scripture]. Lyons.

Arkoudas, K., \& Bringsjord, S. (2009). Propositional Attitudes and Causation. International Journal of Software and Informatics, 3(1), 47-65

Bringsjord S., \& Licato J. (2015). By Disanalogy, Cyberwarfare is Utterly New, Philosophy and Technology. doi:10.1007/s13347-015-0194-y

Caspi-Reisfeld, K. (2001). Women Warriors during the Crusades 1095-1254, In: S. B. Edgington, S. Lambert (Eds), Gendering the Crusades. (pp. 94 - 107). University of Wales Press.

Jaynes, J. (1976). The origin of consciousness in the breakdown of the bicameral mind. Mifflin: Houghton. Moody, E. (1958). Empiricism and metaphysics in medieval logic. Philosophical Review, 67(2), 45-163.

Tarabotti, A. (writing as Galerana Barcitotti). (1651). Che le donne siano della specie degli huomini: Difesa delle donne [Women do belong to the human race: a defence of women], Norimbergh, Par Iuvann Cherchenbergher. 